\title{
Covid-19 has changed the way global employers conduct business
}

Impacts of the pandemic have led to outcomes that include more flexible work environments.

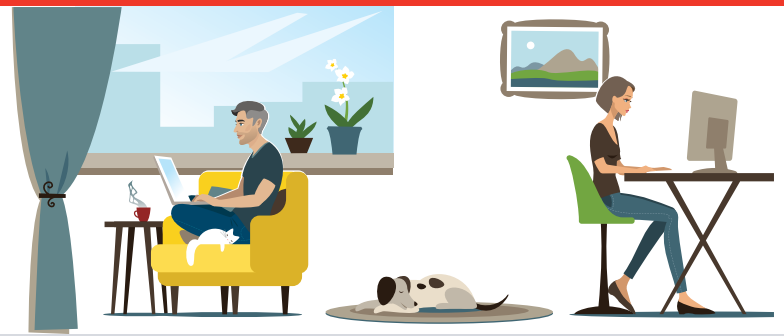

As a direct result of Covid-19, global companies have:

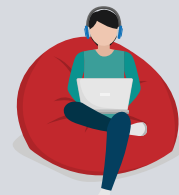

$54 \%$ Allowed staff to
work remotely more often or at all

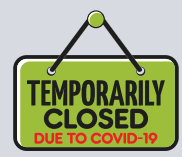

$18 \% \begin{aligned} & \text { Closed the } \\ & \text { business }\end{aligned}$

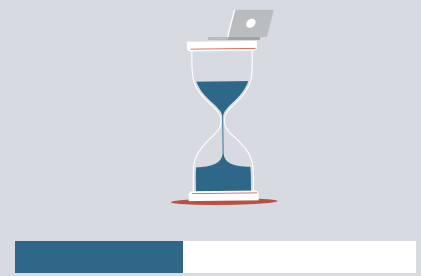

$42 \%$ Reduced hours

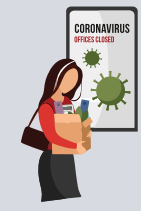

$14 \%$ Laid off

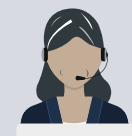

$34 \%$ Changed how provides goods or services

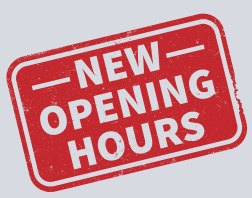

$8 \%$ Increased hours

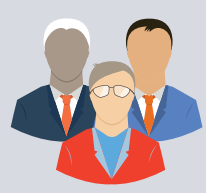

$23 \%$ Hired fewer previously planned

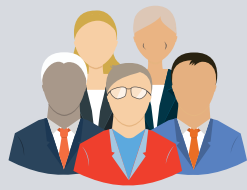

$6 \%$ Hired more workers planned

Even in these unprecedented times, $83 \%$ of global employers deem a multigenerational workforce critical to business growth and success. More than half of global employers have begun or expanded remote working, which has proven that workers across all ages have the technological skills to make flexible work options successful. Embracing these options can help enable a multigenerational workforce.

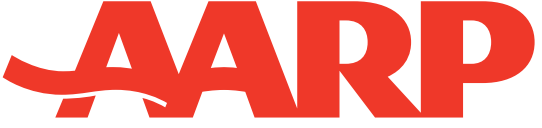

Real Possibilities
Results are from 4,238 global employers surveyed in April/May of 2020. The full issue brief and annotated questionnaire can be found at www.aarpinternational.org/LLEL

For more information on the survey, contact Rebecca Perron at rperron@aarp.org. DOI: https://doi.org/10.26419/res.00399.004 